\title{
Alguns aspectos do coronelismo brasileiro na perspectiva weberiana
}

\author{
Some aspects of Brazilian coronelismo in the Weberian perspective
}

\author{
Murilo Vilarinho ${ }^{1}$
}

Doi: $10.36066 /$ compcs.v1i23.10923

Resumo: O coronelismo brasileiro foi uma forma específica de condução política, desenvolvida durante a República Velha. Sua origem remonta ao Primeiro Reinado. O poder emanado dos coronéis abrangia as dimensões local, regional e nacional - espaços em que eram observadas as dominações política, econômica e social do coronel sobre a sociedade. Partindo do exposto, este ensaio objetiva discutir alguns aspectos referentes ao coronelismo, principalmente, no que diz respeito aos conceitos de poder e dominação em Max Weber.

Palavras-chave: Coronelismo brasileiro, poder, dominação, Max Weber.

\begin{abstract}
Coronelismo in Brazil was a specific form of political power developed during the Old Republic, whose origin dates back to the First Empire. The power emanating from the coronel's dimensions covered local, regional and national - spaces were observed domination the political, economic and social environment on society. Thus, this essay is to discuss some aspects of social coronelismo, with the aim to understand them as from the power and domination concepts in Max Weber.
\end{abstract}

Keywords: Brazilian coronelismo, power, domination, Max Weber.

A presente reflexão busca analisar o coronelismo, considerando-se, em termos de temporalidade, o período da República Velha, quando esse se desenvolveu como sistema social e político.

É verdade que, apesar de o coronelismo ter-se findado há algum tempo, não significa dizer que seus resquícios também se exauriram; ao contrário, esses ainda sobrevivem na mentalidade e atitudes do brasileiro que detém poder, em alguma medida.

Em suma, este escrito não se aterá às minúcias históricas do sistema coronelista, embora elas sejam necessárias na reconstrução do contexto; mas, sim, aos principais aspectos que circundaram tanto as relações sociais entre coronel e sociedade local quanto aos conceitos weberianos de dominação e poder que ajudam a explicar esse fenômeno social estudado com afinco pelo intelectual Vitor Nunes Leal.

\footnotetext{
${ }^{1}$ É politólogo pela PUC-GO. Atualmente, é docente da Faculdade de Ciências e Tecnologia, da Universidade Federal de Goiás. murilochv@yahoo.com.br Compocs, v1, n 23 - jul -dez 202
} 
O coronelismo, no Brasil, pode ser identificado como fenômeno político, econômico, social, psicológico e cultural que remonta aos tempos da República Velha, quando a condução política dos coronéis, na maioria, advindos do Exército, conforme a compreensão de Raymundo Faoro (1979), era quase que autoritária. Poder absoluto, clientelismo, voto de cabresto eram alguns dos mecanismos de que se serviam esses chefes locais, com o fito de organizar e de determinar a vida em sociedade, após a queda do Império de D. Pedro II.

O conceito de coronelismo não é muito indiferente ao entendimento de caudilhismo.

Dessa forma,

Com o termo Caudilhismo nos referimos ao regime imperante na maior parte dos países da América espanhola, no período que vai dos primeiros anos da consolidação definitiva da Independência, em torno de 1820 , até 1860 , quando se concretizaram as aspirações de unificação nacional. O termo, de origem espanhola, é o adotado no uso corrente e científico, em referência a esse fenômeno. O Caudilhismo é caracterizado pela divisão do poder entre chefes de tendência local: os caudilhos. Estes líderes, geralmente de origem militar, oriundos, em sua grande maioria, da desmobilização dos exércitos que combateram nas guerras de independência, de 1810 em diante, provinham, em certos casos, de estratos sociais inferiores ou de grupos étnicos discriminados (mestiços, índios, mulatos, negros). Para grande parte deles, o Caudilhismo, com sua organização paramilitar, constituiu um canal de mobilidade vertical. Valiam-se do seu magnetismo pessoal na condução das tropas, que haviam recrutado geralmente nas áreas rurais e mantinham como reses requisitadas, em ações guerreiras, seja contra o ainda mal consolidado poder central, seja contra os seus iguais, com o apoio dos senhores locais. Esse poder carismático, exercido ao mesmo tempo de forma autoritária e paternalista, e retribuído com a adesão incondicional dos seus homens (e respectivas mulheres). (BOBBIO, 1998, p.166).

O entendimento de caudilhismo assemelha-se ao de coronelismo em muitos elementos. Ambos os foram típicos sistemas da Américas espanhola e portuguesa, formados por um senhorio, cujo artífice do poder de mando era portador de carisma, detinha autoridade e 
apresentava-se, de modo patriarcal, para a sociedade. Nesse sentido, Esses elementos evidentemente proporcionavam ao coronel e, do mesmo modo, ao caudilho destaque no contexto social.

Em termos de fontes literárias que discutem o assunto, Os Donos do Poder, de Raymundo Faoro; O mandonismo local na vida politica brasileira e outros ensaios, de Maria Isaura Pereira de Queiroz e Coronelismo, Enxada e Voto, de Victor Nunes Leal, apresentam perspectivas teóricas necessárias para se iniciar uma discussão sobre o coronelismo, porque são fontes especializadas no assunto.

Além delas, outro recurso bibliográfico dos mais importantes é a obra de Max Weber, Economia e Sociedade e Metodologia das Ciências Sociais. Sua teorização sociológica trata, de modo detido, do poder, da dominação e das relações que envolvem ambas as vertentes ferramentas úteis para análise da figura do coronel, bem como o modo como se inseriu no dia a dia da República Velha.

Analisar o tema coronelismo é justificável para o campo das Ciências Sociais; pois, ao refletir esse sistema que estruturou a vida do brasileiro, durante algum tempo, é possível entender não apenas as relações sociais, processadas naquele momento histórico, mas também os fatores que caracterizavam as ações do coronel em relação à sociedade.

Weber não pesquisou sobre o coronelismo brasileiro. Também não escreveu sobre esse sistema, mas legou conceitos capazes de possibilitar ao estudioso algumas noções sobre o fenômeno, em xeque, que é similar ao caudilhismo, estrutura social e política mencionada pelo sociólogo alemão. Em resumo, estudar Weber é agrupar condições para tecer inferências e pressupostos sobre os tempos do coronelismo nacional.

Historicamente, o coronelismo pode ser entendido, segundo a concepção de Queiroz (1976, p.163), como "uma forma específica de poder político brasileiro que floresceu durante a Primeira República ${ }^{2}$, e cujas raízes remontam ao Império (...)”. Nesse sentido, o coronelismo surge na República Velha como um sistema político oficial, no qual os chefes políticos (coronéis) exerciam poder de modo particular sobre seus domínios. O modelo republicano federalista em consonância com a emergência das oligarquias agrárias foi o pano de fundo por meio do qual o coronelismo se estabeleceu.

\footnotetext{
${ }^{2}$ O Governo de Campo Salles (1898-1902) caracterizou um momento histórico do Brasil em que o coronelismo esteve no auge, haja vista que a política de governadores implementada por ele era baseada em um acordo político entre Estado e oligarquias agrárias, cabendo a essas o papel de manter a instabilidade nos estados da República. Por fim, a escolha de representantes políticas nos estados era totalmente influenciada e fraudada pelos coronéis que naquela época eram apêndices político estratégicos do governo central.
} 
Destarte, pensa-se que o coronelismo foi uma espécie de poder paralelo, ou apêndice do poder maior (Estado republicano) que se utilizava deste para seus fins.

Por coronelismo, em um prisma sociológico, entende-se como:

(...) um compromisso, uma troca de proveitos entre o poder público, progressivamente fortalecido, e a decadente influência social dos chefes locais, notadamente dos senhores de terra. Não é possível, pois, compreender o fenômeno sem referência à nossa estrutura agrária, que fornece a base de sustentação das manifestações de poder privado ainda tão visíveis no interior do Brasil (LEAL, 1997, p.40).

No que concerne às origens do coronelismo, nota-se que elas situam-se no Império, quando os coronéis ocupavam os postos da Guarda Nacional ${ }^{3}$. Durante o Império, a Guarda Nacional tinha a tarefa de defender e proteger a harmonia do Estado, o Governo Imperial e a Constituição do Império.

Em virtude disso, ao longo de quase um século, em nossos municípios, havia um regimento da Guarda Nacional e o posto de coronel era cedido ao chefe político da comuna, para tanto, de acordo com Queiroz (1976, p.164) "os chefes locais mais prestigiosos automaticamente ocupavam os postos mais elevados, que eram os coronéis (...)”.

Com a Proclamação da Independência em 1822, a Guarda auxiliou na manutenção da ordem, prevenindo revoltas e promovendo o policiamento local. Todavia, quando foi proclamada a República em 1889, Queiroz (1976, p. 164) menciona que foi extinta a “(...) Guarda Nacional pouco depois da Proclamação da República, persistindo (...) a denominação de coronel, outorgada (...) pela população àqueles que pareciam deter entre suas mãos, grandes ou razoáveis parcelas de poder econômico e político".

Em consequência disso, observa-se que os coronéis deixam de pertencer a antiga Guarda Nacional, estendendo o poder que possuíam, nos tempos do Império, sobre os municípios, os estados e até mesmo sobre a esfera nacional.

\footnotetext{
3 A lei de 18/08/1831 criou a Guarda Nacional em substituição aos extintos Corpos de Milícias dos Guardas Nacionais e Ordenanças, com a competência de defender a constituição, a liberdade, a independência e a integridade do Império; para manter a obediência às leis, conservar ou restabelecer a ordem e a tranqüilidade pública e auxiliar o exército de linha na defesa das fronteiras e costas. Organizada em todo o império por municípios, subordinava-se aos juízes de paz, juízes criminais, aos presidentes de província e ao ministro da Justiça. ( In: Arquivo Nacional, Série Guerra - Guarda Nacional (IG13), referência: BR AN,RIO 9R).
} 
Tendo exposto, de maneira resumida o contexto histórico - social, em que o coronelismo emergiu, o ensaio discorre sobre a figura do coronel, portanto:

O coronel se define pelo poder político: quando o domínio sobre o qual o protetor atua é muito extenso e reúne grande número de eleitores, dá-se a este o nome de coronel, porque outrora ele era com frequência coronel da Guarda Nacional. O coronelismo é então a forma tomada por essa proteção (BLONDEL apud QUEIROZ, 1976, p.173).

Além disso, Faoro completa a descrição:

O conceito entrou na linguagem corrente por via do estilo social, inclusive na vida urbana, com predominância sobre sua função burocrática e política. Homens ricos, ostentando vaidosamente os seus bens de fortuna, gastando os rendimentos em diversões lícitas e ilícitas, foram tais coronéis os que deram ensejo ao significado especial que tão elevado posto militar assumiu, designado demopsicologicamente o indivíduo que paga as despesas (...) o coronel, antes de ser um homem político é um líder econômico (...) (FAORO, 1925, p.622)

Visualiza-se que o coronel era um homem rico, dono de terras, uma espécie de “elemento sócio-econômico polarizador" (QUEIROZ, 1976). Com base nessa fala de Queiroz (1976), acredita-se que em face à sociedade local a qual o coronel monopolizava e estabelecia laços de compadrio com o povo, gravitava em torno dele a sua gente, ou melhor, a sua clientela, composta pela família, pelos parentes, pelos empregados e pelos agregados entre outros. Era nesse meio onde o coronel desenvolvia seu poder e dominação.

O coronel era um verdadeiro homem cordial o qual de acordo com Sérgio Buarque de Holanda (1995, p.147) pode ser caracterizado pela:

(...) A ilhaneza no trato, a hospitalidade, a generosidade, virtudes tão gabadas por estrangeiros que nos visitam, representam, com efeito, um traço definido do caráter brasileiro, na medida, ao menos, em que permanece ativa e fecunda a influência ancestral dos padrões de convívio 
humano, informados no meio rural e patriarcal. Seria engano supor que essas virtudes possam significar "boas maneiras", civilidade. São antes de tudo expressões legítimas de um fundo emotivo extremamente rico e transbordante. Na civilidade há qualquer coisa de coercitivo - ela pode exprimir-se em mandamentos e em sentenças.

No que circunscreve ao poder e a dominação do coronel, o voto e o número de eleitores fiéis (curral eleitoral) eram os aspectos que conferiam o domínio e o poderio do mesmo em sua região. Contudo, o voto representava o recurso primordial para a quantificação, austeridade e proeminência desse chefe político.

Quando a questão era o voto, por vezes, esses não eram obtidos de forma pacífica, isto é, não eram consentidos livremente pelos indivíduos de determinada sociedade. Neste caso, os coronéis sempre recorriam aos recursos de opressão e violência, praticando atos de crueldade os quais eram perpetrados na contabilidade dos votos.

Partindo desse pressuposto, a ideia de poder na concepção weberiana seria a probabilidade de impor a própria vontade dentro de uma determinada relação social, tendo em vista a resistência e a natureza dessa probabilidade. Essa perspectiva ilustra o poder desferido pelo coronelismo, ou seja, o uso prerrogativa da violência para alcançar a obediência, obtendo, por fim, o que se almejam -- o voto, por exemplo.

No coronelismo, o voto era o instrumento que conferia poder ao chefe local, pois, quando se proclamou a República em 1889 e. em 1891 foi promulgada a nova Constituição que:

Outorgou o direito de voto a todo cidadão brasileiro ou naturalizado que fosse alfabetizado; assim, pareciam extintas as antigas barreiras econômicas, políticas, e um amplo eleitorado poderia teoricamente exprimir livremente sua escolha. Todavia, verificou-se desde logo que a extensão do direito de voto a todo cidadão alfabetizado não fez mais do que aumentar o número de eleitores rurais e citadinos, que continuaram obedecendo aos mandões políticos existentes. A base da antiga estrutura eleitoral se alargara, porém os chefes políticos locais e regionais se mantiveram praticamente os mesmos, e continuaram elegendo para as câmaras, para as presidências dos estados, para o senado, seus parentes, seus aliados, seus apaniguados, seus protegidos (QUEIROZ, 1976, p.163). 
Verifica-se que a passagem do Império para República extinguiu a Guarda Nacional, emergindo dela a classe dos coronéis -- os tutores da antiga Guarda. Essa classe mandatária se beneficiou com a promulgação da primeira Constituição republicana, a qual adotou um sistema eleitoral em que o voto era aberto e cada chefe político tinha, portanto, pleno controle sobre seus eleitores -- nesse sistema a democracia era mera ficção.

Em relação ao voto durante o período do coronelismo, certifica-se que o indivíduo votante era não só pressionado pelo coronel, como também seu voto figurava como mercadoria passível de ser comprada ou trocada por favores. A esse respeito, Victor Nunes Leal (1977) ilustra os dois lados da moeda chamada indivíduo que votava, quem estava a mercê dos chefes municipais e dos coronéis, que conduziam "magotes de eleitores como que toca tropa de burros" ${ }^{4}$, de uma lado, e de outro, havia a situação política dominante do Estado o qual dispunha “(...) do erário, dos empregos, dos favores e da força policial, que possui, em suma, o cofre das graças e o poder da desgraça" 5

Enfim, em todos os quadrantes, o voto era tutelado pelo chefe político através, como sendo um bem que só ele poderia dispor ao seu bel prazer. Como nos lembra Queiroz (1976, p.182) “o indivíduo dá seu voto porque já recebeu seu benefício, ou porque ainda espera recebê-lo".

É interessante lembrar que a massa do eleitorado excluía, portanto, a mão de obra rural das fazendas -- parcela analfabeta da comunidade. Esses grupos formavam-se os capangas que trabalhavam para o coronel. O eleitorado, por seu turno, era composto pelos pequenos funcionários, artífices e vendeiros que habitavam os vilarejos.

Sobre o eleitor, a Constituição de $1891^{6}$ assinala:

Art 70 - São eleitores os cidadãos maiores de 21 anos que se alistarem na forma da lei. $\S 1^{\circ}$ - Não podem alistar-se eleitores para as eleições federais ou para as dos Estados: $1^{\circ}$ ) os mendigos; $2^{\circ}$ ) os analfabetos; $3^{\circ}$ ) as praças de pré, excetuados os alunos das escolas militares de ensino superior; $4^{\circ}$ ) os religiosos de ordens monásticas, companhias, congregações ou comunidades de qualquer denominação, sujeitas a

\footnotetext{
${ }^{4}$ Ibid, 1977.

${ }^{5}$ Ibid, 1977.

${ }^{6}$ BRASIL. Constituição da República dos Estados Unidos do Brasil ( de 24 de fevereiro de 1891). Disponível em: http://www.planalto.gov.br/ccivil 03/Constituicao/Constitui\%C3\%A7a091.htm. Acesso em: 10 jul 2012.
} 
voto de obediência, regra ou estatuto que importe a renúncia da liberdade Individual. (BRASIL, CONSTITUIÇÃO DE 1891).

A Constituição de 1891, ou seja, da República Velha, aponta os indivíduos que estavam à margem do sistema eleitoral, sendo eles uma grande parcela da população brasileira.

Em se tratando da dominação que emanava da figura do coronel -- o mandatário do senhorio local, quem exercia dominação sobre a população; é do pensamento weberiano que surge um conceito importante para se compreender a justificação desse poder, assim sendo:

(...) isso é, a dominação é a probabilidade de encontrar obediência a uma determinada ordem, pode ter seu fundamento em diversos motivos de submissão, pode ser determinada diretamente de uma constelação de interesses, ou seja, considerações racionais de vantagens e desvantagens (referentes aos meios e fins) por parte daquele que obedece, mas também pode depender de um mero costume, ou seja, do hábito cego de um comportamento inveterado (...). (WEBER, 1992, p.346).

Acredita-se que a dominação emanada do coronel para a população primava pela obediência de seus eleitores, ou melhor, de sua clientela em outra acepção.

Os dominados, por conseguinte, vislumbravam receber os benefícios e a proteção que a figura do coronel poderia proporcionar. Em vista disso, a submissão era a marca do eleitorado, até mesmo porque eram coagidos através da violência, caso não seguissem os ditames do chefe político.

A mentalidade da sociedade naquele contexto não contrapunha às fronteiras da dominação advindas do coronelismo, uma vez que tal estrutura caudilhista atravessou gerações; tornando-se, no entanto, um costume ou um hábito cego, nas palavras de Weber, ${ }^{7} a$ obediência sem precedentes.

Dito isso, seguindo a ótica weberiana, percebe-se que Max Weber teorizou aquilo que ele designou como sendo os tipos puros de dominação. Para o sociólogo há a dominação racional, tradicional e carismática. Sobre eles, Weber assevera:

\footnotetext{
${ }^{7}$ Ibid, 1992.
} 
Há três tipos puros de dominação legítima. A vigência de sua legitimidade pode ser, primordialmente: 1 . de caráter racional: baseada na crença na legitimidade das ordens estatuídas e do direito de mando daqueles que, em virtude dessas ordens, estão nomeados para exercer a dominação (dominação legal), ou 2. de caráter tradicional: baseada na crença cotidiana na santidade das tradições vigentes desde sempre na legitimidade daqueles que, em virtude dessas tradições, representam a autoridade (dominação tradicional), ou, por fim, 3. de caráter carismático: baseada na veneração extracotidiana da santidade, do poder heróico ou do caráter exemplar de uma pessoa e das ordens por esta reveladas ou criadas (dominação carismática). (WEBER, 2004, p.141).

Max Weber sintetizou o significado de cada tipo de dominação. Todavia, no que diz respeito ao coronelismo, atesta-se que para precisar qual tipo dominação se encaixaria no perfil do coronel, seria necessário mesclar características de dois tipos de dominação, fala-se da dominação tradicional e da dominação carismática. Assim sendo, ambas poderiam revelar o tipo de dominação levada a cabo pelo coronel em sua sociedade.

A dominação tradicional pode ser entendida como aquela em que a:

(...) autoridade não se baseia no dever de servir a uma "finalidade impessoal e objetiva", (como acontece na dominação racional) obedecendo a normas abstratas, mas justamente ao contrário: na submissão ao pater-familias, em virtude de uma devoção rigorosamente pessoal. (RODRIGUEZ, 2006, p.13).

No caso do coronelismo, seria o coronel uma espécie de pai do povo, o qual contaria com a devoção da população que se manteria submissa. Por este prisma, Weber (2004) divide a dominação tradicional em feudal e em patrimonial. Assim sendo, no patrimonialismo, o público é uma extensão do domínio doméstico do soberano.

A respeito dessa afirmação, nota-se que, no patrimonialismo, há:

(...) uma extrapolação da política e da administração domésticas para fora de seu círculo familiar. Há, pois, uma adaptação de métodos e posturas éticas às novas circunstâncias, mas em essência prevalece o 
espírito original. Reproduz-se no Estado o modelo da política e da administração domésticas. [...] até a postura moral dos funcionários reproduz o modelo de administração privada da casa do rei. [...] o Estado Patrimonial converte-se em domínio privado do monarca, uma extensão de sua casa real, de sua família e de seu patrimônio pessoal. (ZACARO, 1994, p.20-21).

Em relação ao coronelismo, o mesmo pode ser percebido como instituição por meio da qual a massa é manipulada, inclusive os recursos públicos em proveito pessoal do coronel, quem, nas palavras de Zancaro, ${ }^{8}$ utiliza-se de: (...) favores, privilégios, recompensas, regalias e sinecuras aos súditos particularmente aos mais fiéis. (...) Grandes massas populacionais carentes são manipuladas através de um assistencialismo que atende aos interesses e necessidades mais sensíveis, angariando em troca a base indispensável para a manutenção da dominação.

Em face do exposto, verifica-se que não são apenas os caracteres imediatos (terras, dinheiro, favores, opressão etc.) que caracterizam a dominação e poder emanado do coronel. Há ainda outro elemento em Weber que responde juntamente com a dominação tradicional, a proeminência social - política do coronel, fala-se do carisma.

Entende-se que a riqueza é um trunfo importante na manutenção do poder e da dominação, mas ela por si só não assegura a proeminência do chefe político frente às massas. Entretanto, a base econômica e política somam-se ao pensamento de Faoro (1979) que menciona que o poder do coronel está além da riqueza econômica, ou seja, ele manda e é obedecido porque o seu poder é reconhecido pela sociedade através de pacto não escrito.

Tal obediência por parte do povo pode ser explicada pelo conceito de dominação carismática em Weber. Acredita-se que é o carisma o ingrediente final o qual encanta as mentes do povo em relação ao coronel.

Com base em Weber (1992) e Queiroz (1976), no que se refere ao carisma, virtude que somada à base econômica (fortuna e prestígio), ela propiciava a liderança do coronel e a sua preponderância sobre o corpo social. Nesse sentido, verifica-se:

(...) carisma-conjunto de dotes pessoais que impõe um indivíduo aos outros, fazendo com que estes lhe obedeçam, tornando suas ordens

\footnotetext{
${ }^{8}$ Ibid, p.22.
} 
indiscutíveis justamente porque emanam dele. O carisma era segundo Weber, a virtude dos caudilhos; todo coronel, pequeno ou grande, era um caudilhete, ou um caudilho (...). Esta qualidade indispensável explica porque, dentro do grupo da parentela, a liderança não passava diretamente de pais a filhos; o chefe escolhia para seu continuador aquele que representasse as qualidades exigidas, podendo a designação recair até sobre um estranho que a família tivesse adotado desde que possuía bens e fortuna (...). A liderança coronelística, que era sempre uma liderança econômica, e uma liderança de parentelas; assumia além de tudo um aspecto nitidamente carismático (...) só chegava à grande chefe se apresentasse aquela inexplicável qualidade que despertava a adesão afetiva e entusiástica dos homens, levando-os espontaneamente a obediência, qualidade que concorria para reforçar a solidariedade interna do grupo (QUEIROZ, 1976, p. 198-199).

O carisma, enquanto um conjunto de dotes pessoais carisma, foi um elemento preponderante e decisivo na proeminência dominação do coronel com relação sua a parentela e a sociedade patriarcalista vista no Brasil do contexto em voga.

O carisma fora estudado por Weber e como exemplo, este utilizou da figura dos caudilhos que eram líderes locais nos antigos domínios da América colonial hispânica.

É verdade que em muito diferiram os Caudilhos dos vices-reinos dos coronéis das terras brasilis, mas o dom que tangencia ao sobrenatural, isso é, a virtude carismática é um traço semelhante a ambos os líderes político, social, das parentelas.

Finalmente, foi o carisma o mecanismo inexplicável de acordo com Queiroz (1976) que justificava, além da opressão e da violência, o sucesso da dominação e do poder sobre a sociedade, por parte do coronel - o homem cordial de Sérgio Buarque de Holanda.

\section{Considerações Finais}

O coronelismo brasileiro conformou um contexto social e político significante para a compreensão de história de formação do povo brasileiro, uma vez que, neste momento, configuraram-se relações de poder (isso é, o poder do coronel ligado à terra, em favor da 
instituição do clientelismo) que ainda, em plena contemporaneidade, é observado na prática política de muitos demiurgos que fazem uso d a máquina pública do poder.

Apreendeu-se que, de fato, a dominação da figura coronelística não era apenas legitimada pelo aspecto econômico, tampouco político, mas acima de tudo pelo carisma nos moldes weberiano, elemento sobre humano típico dos profetas, feiticeiros, comandantes militares, e que em última instância não era acessível a qualquer pessoa.

De acordo com o ponto acima referendado, uma consideração sumária é importante de ser salientada, ou seja, a estrutura coronelística não era uma estrutura hereditária, a dominação sobre uma dada clientela não era exercida passando de pai a filhos e estes a netos. Ao contrário, o coronel, além de ser um homem rico, ligado à posse da terra, ele possuía algo que transcendia aos limites do cotidiano, capaz de liderar a um grande grupo e sua liderança produzir mudanças significativas nas relações sociais marcadas pela racionalidade. Ou seja, frente ao sistema de votos que na sociedade brasileira se inauguraram com a Constituição de 1891, os chefes do mandonismo cooptavam os votos da enxada ${ }^{9}$ a bel prazer utilizando do carisma como ferramentas para aperfeiçoar o processo político que beneficiava em grande medida uma pequena minoria (rica) em contraposição a uma grande minoria que ficava à margem do plano político do sistema coronelista e do plano político nacional.

O coronelismo foi um entrave, em alguma medida, ao desenvolvimento da do ideal democrático de República, pensado os valores liberais. Segundo observa-se na história da sociedade brasileira, a instituição coronelística e sua projeção político - administrativa (uma subespécie de autoritarismo, patrimonialista) corroboraram o retardamento da construção de um Brasil moderno e republicano, de fato, se comparado ao rol das nações do Velho Mundo e aos irmãos americanos; todavia, o quadro brasileiro pautado no período do coronelismo se modifica a partir da Revolução de 1930 com o Governo de Getúlio Vargas, quando na cena pública nacional há uma revolução Burguesa, parafraseando Florestan Fernandes (1976). A partir dessa época, há uma considerável migração campo - cidade; nesse sentido, tendo acesso a educação e a informação a população começa a se politizar mais, salvo aqueles que permaneceram na zona rural.

Finalmente, foi somente após a Constituição de 1988 que o brasileiro adquiriu maior consciência de sua condição cidadã em contraposição à condição de cliente, de animal

\footnotetext{
9 De acordo com leitura de Vitor Nunes Leal (1977). A enxada palavra que figura no titulo de sua obra, Coronelismo, enxada e voto, foi usada neste momento com significado correspondente a povo, população rural, simples, atrasada intelectualmente e civicamente em contrapartida a elite da terra - coronéis e a elite política brasileira.
} 
político (não no sentido aristotélico de homem político enquanto participante da vida na polis) que sempre foi conduzido à currais eleitorais, pressionado ao voto de cabresto.

\section{Referências}

BOBBIO, Norberto et al. Dicionário de Política. Brasília: UNB, 2003.

BURSZTYN, Marcel. $O$ Poder dos Donos - Planejamento e Clientelismo no Nordeste. 2 ed. Petrópolis: Vozes, 1985.

CAMPOS, Flavio de Dolhnikoff. História do Brasil. Brasília: FUNAG, 2001.

FAORO, Raymundo. Os donos do poder: formação do patronato político brasileiro. 5 ed. Porto Alegre: Editora Globo, 1979.

FERNANDES, Florestan. A Revolução Burguesa no Brasil. Ensaio de interpretação sociológica. Rio de Janeiro: Zahar, 1976.

HOLANDA, Sérgio B. Raízes do Brasil. São Paulo, SP. Companhia das letras, 1995.

LEAL, Vitor Nunes. Coronelismo, enxada e voto: o município e o regime representativo no Brasil. 2 ed. São Paulo: Alfa- Omega, 1977.

QUEIROZ. Maria Isaura Pereira de. O Mandonismo Local na Vida Política do Brasil e Outros Ensaios . São Paulo: Alfa- Omega, 1976.

RODRÍGUEZ, Ricardo Vélez. Patrimonialismo - e a realidade latino-americana. Rio de Janeiro: Documenta Histórica Editora, 2006.

ZANCANARO, Antonio Frederico. A Corrupção Político-Administrativa no Brasil. São Paulo: Editora Acadêmica, 1994.

WEBER, Max. Economia e Sociedade. Brasília: Editora UNB, 2004.

WEBER. Max. Metodologia das Ciências Sociais. São Paulo: Editora da Universidade Estadual de Campinas, 1992. 